\title{
Outbreaks of salmonella infection in hospitals in England and Wales 1978-87
}

\author{
Carol A Joseph, Stephen R Palmer
}

\begin{abstract}
A total of 248 outbreaks of salmonella infection in hospital affecting over 3000 patients and 110 associated deaths were ascertained in England and Wales in 1978-87, compared with 522 outbreaks of salmonella in 1968-77. The largest reduction was found in outbreaks from children's units and maternity units. Fifty seven $(24 \%)$ outbreaks were considered to be due to foodborne salmonellosis, and $70(30 \%)$ were reported as person to person spread of the infection. The psychiatric hospital was the type of hospital in which foodborne outbreaks most often occurred, but the risk of being affected in an outbreak not due to food seemed to be highest in maternity units.

Better control of infection and better surveillance should lead to earlier investigation and control of outbreaks.
\end{abstract}

\section{Introduction}

Outbreaks of salmonella in hospitals are of special concern, firstly, because of the increased susceptibility of hospital patients, in whom there is a high associated fatality rate, and, secondly, because outbreaks and control measures can seriously disrupt hospital services. ${ }^{\prime}$ The outbreak in 1984 at the Stanley Royd Hospital, where there were over 400 cases and 19 deaths, led to a public inquiry ${ }^{2}$ and recommendations for the investigation, control, and prevention of such outbreaks. In this paper we report the trends in the occurrence of outbreaks in hospitals in England and Wales.

\section{Method}

Reports of outbreaks of salmonellosis in hospitals in England and Wales were received by the Public Health Laboratory Service Communicable Disease Surveillance Centre from (i) public health and hospital laboratories; ; ${ }^{3}$ ii) reports from medical officers for environmental health and environmental health officers $^{4}$ from 1980 onwards; (iii) field investigation reports to staff at the Communicable Disease Surveillance Centre; (iv) correspondence; and $(v)$ telephone reports. In the following analysis outbreaks were considered to be foodborne if there were two or more related clinical cases or laboratory confirmed infections in which a food was suspected or proved by the reporting laboratory to be the source of infection, or if the salmonella species causing the outbreak in patients was isolated from the faeces of staff in the hospital kitchen or from an environmental reservoir in the kitchen.

Statistics for the average number of beds used daily in the different patient groups in England and Wales were obtained from the Department of Health and Social Security ${ }^{5}$ and the Welsh Office ${ }^{6}$ and multiplied by 365 to estimate the number of occupied bed days per year in particular types of hospitals or wards. We then calculated the ratio of outbreaks and outbreak cases to bed days used. Data for outbreaks occurring during 1968-77 were obtained from a previous publication.

\section{Results}

Thirteen outbreaks were reported only by correspondence or telephone, and these were not included in the following analysis. The other reports showed that the number of outbreaks in hospitals fell from 138 in 1978-82 to 97 in 1983-7 (figure).

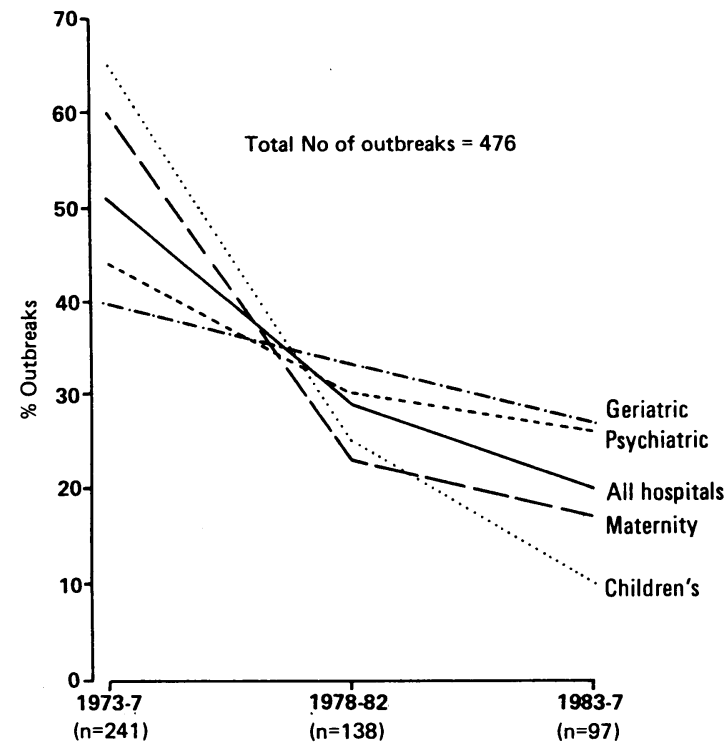

Percentage of outbreaks of infection with salmonella in various types of hospitals or units in England and Wales, 1973-87

\section{SOURCE OF INFECTION}

Foodborne

Fifty seven (24\%) reported outbreaks affecting 1862 people were attributed to food poisoning, but the causative organism was isolated from food in only five outbreaks. Three of these five outbreaks were in psychiatric hospitals and comprised one outbreak associated with hens' eggs and two outbreaks from contaminated chicken. The other two confirmed foodborne outbreaks affected only hospital staff. In half of the outbreaks a specific food was named as the presumptive cause. These were poultry (13), various cooked meats (seven), eggs (three), sandwiches (two), and other foods (four).

In eight suspected foodborne outbreaks kitchen practices were said to be unsatisfactory. For example, in an outbreak affecting 65 people in a general hospital a banana custard was prepared and left uncovered for several hours on trolleys next to a meat defrosting
Correspondence to: 
area. In another outbreak affecting 22 hospital staff sandwiches were prepared on a surface also used for defrosting poultry. The sandwiches were then dispatched to various parts of the hospital, where they remained unrefrigerated for up to eight hours. At one psychiatric hospital three outbreaks caused by the same organism occurred in 1985-7, and investigations eventually showed a vegetable mill from the hospital kitchen to be the likely source of contamination.

In 32 of the 57 foodborne outbreaks food handlers were known to be infected, but in only two outbreaks was the food handler reported to be the source of infection. In one of these a food handler returned to work with diarrhoea after a holiday in Spain, and in the other a chef was thought to have intermittently contaminated the food, leading to an outbreak affecting five people.

\section{Person to person spread}

Seventy one $(30 \%)$ outbreaks affecting 558 people were attributed to person to person spread, of which 31 were traced to the admission of a patient with diarrhoea. In four outbreaks faulty bedpan washers were implicated, and in a further two outbreaks the vehicle of infection was believed to be contaminated gastroscopes. In eight person to person outbreaks it was known that closing the ward or hospital was considered necessary to control the spread of infection.

\section{Unknown}

Altogether 107 (46\%) outbreaks affecting 907 people were reported for which no information of the source of the infection was given.

\section{SIZE OF OUTBREAKS}

Foodborne outbreaks were larger than other salmonella outbreaks with an average of 33 cases per outbreak (table I). Two fifths of foodborne outbreaks and three quarters of person to person outbreaks or outbreaks where the source was unknown affected 10 or fewer people. Salmonella typhimurium infection affected more than 100 people in each of four foodborne outbreaks and one of unknown source. One of the foodborne outbreaks was at the Stanley Royd Hospital in 1984, where over 400 people were affected and 27 died, 19 of them directly from salmonella infection.

\section{TYPE OF HOSPITAL OR WARD AFFECTED}

One or more outbreaks occurred in $1 \%$ of the estimated total of 2100 hospitals in England and Wales (Department of Health and Welsh Office, personal communication) in 1978-87. Outbreaks were most commonly reported from general, psychiatric, and geriatric wards or hospitals (table I). There were no accurate data on the number of the various types of unit-for example, maternity-during 1978-87, but as an index of the risk of patients being part of a salmonella outbreak we estimated the ratio of outbreaks and outbreak cases occurring in various units to the number of bed days occupied within those units. For the outbreaks where food poisoning was specified the ratio of outbreak cases to occupied bed days was similar for all types of patients (table II), but the ratio of outbreak cases to occupied bed days was higher in psychiatric patients, reflecting the increased size of foodborne outbreaks in psychiatric units. For other salmonella outbreaks the ratio of outbreaks and outbreak cases to occupied bed days was appreciably higher in maternity and children's units while psychiatric units had the lowest ratio.

\section{SEROTYPES}

Thirty seven different salmonella serotypes were recorded: 69 outbreaks were due to $S$ typhimurium, 34 to $S$ enteritidis, and 23 to $S$ virchow (table III). Most outbreaks of $S$ virchow occurred in 1978-83. Outbreaks due to $S$ typhimurium and $S$ enteritidis were reported

TABLE I-Laboratory and field investigation reports of outbreaks of salmonella infection by type of hospital affected in England and Wales, $1978-87$

\begin{tabular}{|c|c|c|c|c|c|c|c|c|c|c|}
\hline \multirow[b]{2}{*}{ Type of hospital or ward } & \multicolumn{2}{|c|}{ Foodborne } & \multicolumn{2}{|c|}{ Person to person } & \multicolumn{2}{|c|}{ Unknown cause } & \multirow{2}{*}{$\begin{array}{c}\text { Total } \\
\text { No of } \\
\text { outbreaks }\end{array}$} & \multirow{2}{*}{$\begin{array}{c}\text { Total } \\
\text { No } \\
\text { affected }\end{array}$} & \multirow{2}{*}{$\begin{array}{c}\text { No of } \\
\text { salmonella } \\
\text { related } \\
\text { deaths }\end{array}$} & \multirow[b]{2}{*}{$\begin{array}{c}\text { All } \\
\text { deaths }\end{array}$} \\
\hline & $\begin{array}{c}\text { No of } \\
\text { outbreaks }\end{array}$ & $\begin{array}{c}\text { No } \\
\text { affected }\end{array}$ & $\begin{array}{c}\text { No of } \\
\text { outbreaks }\end{array}$ & $\begin{array}{c}\text { No } \\
\text { affected }\end{array}$ & $\begin{array}{c}\text { No of } \\
\text { outbreaks }\end{array}$ & $\begin{array}{c}\text { No } \\
\text { affected }\end{array}$ & & & & \\
\hline Maternity & 2 & 9 & 10 & 36 & 16 & 71 & 28 & 116 & & 2 \\
\hline Children's & 2 & 4 & 9 & 59 & 6 & 41 & 17 & 104 & & \\
\hline Psychiatric & 19 & 1040 & 5 & 143 & 22 & 115 & 46 & 1298 & 31 & 47 \\
\hline Geriatric & 6 & 47 & 20 & 163 & 18 & 255 & 44 & 465 & 5 & 20 \\
\hline General & 13 & 371 & 10 & 51 & 26 & 352 & 49 & 774 & 2 & 26 \\
\hline Other & 4 & 82 & 10 & 74 & 6 & 21 & 20 & 177 & 1 & 7 \\
\hline Not stated & 2 & 23 & 7 & 32 & 9 & 40 & 18 & 95 & 4 & 6 \\
\hline Staff only & 9 & 286 & & & 4 & 12 & 13 & 298 & & \\
\hline Total & 57 & 1862 & 71 & 558 & 107 & 907 & 235 & 3327 & 43 & 108 \\
\hline Average No of cases affe & & 33 & & 8 & & 8 & & 14 & & \\
\hline
\end{tabular}

TABLE II -Number of outbreaks and outbreak cases per 100000 bed occupied days per year by type of hospital affected in England and Wales, 1978-87

\begin{tabular}{|c|c|c|c|c|c|c|}
\hline \multirow[b]{3}{*}{$\begin{array}{c}\text { Type of } \\
\text { hospital or ward }\end{array}$} & \multicolumn{6}{|c|}{ Outbreaks } \\
\hline & \multicolumn{2}{|c|}{ Foodborne } & \multicolumn{2}{|c|}{ Other salmonella ${ }^{\star}$} & \multicolumn{2}{|c|}{ All } \\
\hline & $\begin{array}{c}\text { Ratio of } \\
\text { outbreaks } \\
\text { to occupied bed days }\end{array}$ & $\begin{array}{c}\text { Ratio of } \\
\text { outbreak cases } \\
\text { to occupied bed days }\end{array}$ & $\begin{array}{c}\text { Ratio of } \\
\text { outbreaks } \\
\text { to occupied bed days }\end{array}$ & $\begin{array}{c}\text { Ratio of } \\
\text { outbreak cases } \\
\text { to occupied bed days }\end{array}$ & $\begin{array}{c}\text { Ratio of } \\
\text { outbreaks } \\
\text { to occupied bed days }\end{array}$ & $\begin{array}{c}\text { Ratio of } \\
\text { outbreak cases } \\
\text { to occupied bed days }\end{array}$ \\
\hline Maternity & $0 \cdot 004$ & 0.02 & 0.051 & $0 \cdot 21$ & 0.06 & 0.23 \\
\hline Children's & 0.005 & 0.01 & 0.034 & 0.23 & 0.04 & $0 \cdot 24$ \\
\hline Psychiatric & 0.004 & 0.21 & 0.006 & 0.08 & 0.01 & 0.30 \\
\hline Geriatric & 0.003 & 0.01 & 0.018 & $0 \cdot 18$ & 0.02 & 0.19 \\
\hline General/other & 0.005 & $0 \cdot 13$ & 0.014 & $0 \cdot 14$ & 0.02 & $0 \cdot 27$ \\
\hline Total & 0.04 & $1 \cdot 31$ & $0 \cdot 14$ & $1 \cdot 29$ & $0 \cdot 18$ & $2 \cdot 6$ \\
\hline
\end{tabular}

^Includes outbreaks of unknown cause.

Source: Department of Health and Social Security. Health and Personal Social Services Statistics for England, Table 4.5.' Department of Health and Social Security. Statistical Bulletin 4/87, Table 6 (for children's beds). Welsh Office. Health and Personal Social Services Statistics for Wales, Table 4.04. ${ }^{\circ}$ 
TABLE III - Laboratory and field investigation reports of outbreaks of salmonella infection in hospitals by 10 most common serotypes in England and Wales, 1978-87

\begin{tabular}{lcccc}
\hline \multicolumn{1}{c}{ Serotype } & Foodborne & Person to person & Unknown cause & Total \\
\hline S typhimurium & 15 & 21 & 33 & 69 \\
S enteritidis & 15 & 9 & 10 & 34 \\
S virchow & 3 & 8 & 12 & 23 \\
S hadar & 6 & 4 & 2 & 12 \\
S panama & 1 & 1 & 9 & 11 \\
$S$ saint-paul & 1 & 2 & 8 & 11 \\
$S$ heidelberg & 2 & 2 & 3 & 7 \\
$S$ infantis & 2 & 2 & 3 & 7 \\
$S$ stanley & 1 & 3 & 4 & 7 \\
S kedougou & 1 & 1 & 88 & 187 \\
\hline Total & 46 & 53 & 108 & 235 \\
Total all & 57 & 70 & &
\end{tabular}

regularly each year, the last serotype being responsible for the highest proportion (36\%) of outbreaks in 1987.

\section{DEATHS}

There were 108 deaths associated with the 3327 cases in hospitals in 1978-87-one death per 31 cases. But in only 43 of these deaths was salmonella infection reported by laboratories or field investigation reports as the primary or contributing cause of death (table I). Thirty six of these deaths were in patients from psychiatric or geriatric hospitals, and 19 were associated with the outbreak at the Stanley Royd Hospital in $1984,{ }^{2}$ the highest number ever recorded from one incident. In 32 cases death was said to be unrelated to the outbreak, and in 33 no information was given as to the cause of death.

\section{Discussion}

The number of salmonella infections in England and Wales each year has increased dramatically over the past 20 years. Despite this trend, and in contrast to the attention paid to outbreaks of salmonella infection in hospitals since that in the Stanley Royd Hospital in 1984, the numbers of reports of outbreaks in hospitals fell steadily over this period: 522 outbreaks were reported in 1968-77 compared with 235 formally reported outbreaks in 1978-87, a 55\% reduction, with the greatest percentage reduction from outbreaks in children's and maternity units (figure). Outbreaks in hospitals now represent a smaller proportion of the total number of all salmonella outbreaks than $\mathbf{1 0}$ years previously. In 1978, 30\% of all outbreaks of salmonella infection in the community occurred in hospitals compared with only $10 \%$ in 1987 , though outbreaks in hospitals contributed $28 \%$ of all outbreak associated deaths from salmonella during this 10 year period.

In almost half the reports the mode of transmission in the outbreaks could not be determined because of lack of information. These outbreaks were similar in size to person to person outbreaks; there were usually fewer than 10 cases per outbreak, and we believe that most were not foodborne. The results of an in depth study of all outbreaks in hospitals in England and Wales in 1981-2 suggested that most small outbreaks of salmonella infection in hospitals were due to person to person transmission. ${ }^{8}$ The risk to patients of being affected by person to person outbreaks or outbreaks of unknown source in our study was greatest in maternity and children's units followed by geriatric wards or hospitals, all places where faecal soiling is more common. In such outbreaks it is difficult to control infection, and in eight the ward or hospital was closed to control spread.

Outbreaks due to foodborne salmonella were most commonly reported in psychiatric hospitals, and the risk of a psychiatric patient being affected in such an outbreak was two to 10 times greater than for other patients. But this was because outbreaks in psychiatric hospitals were larger and not because the risk of an outbreak occurring was greater. This finding may reflect the common design of psychiatric hospitals, where large numbers of patients are fed from one large kitchen, and that the number of cases in a foodborne outbreak is related to the number of people eating the contaminated food. For example, in the outbreak at the Stanley Royd Hospital in 1984 over 400 people were infected from food prepared from one kitchen. Our data show, however, that this outbreak was atypical in size and severity of outbreaks of food poisoning over the past 10 years. The proportion of outbreaks attributed to foodborne infection in 1978-87 was $24 \%$ (range $11-58 \%$ ), and no overall yearly trend was evident. In Scotland for the same 10 years $29 \%$ of the salmonella outbreaks were identified as foodborne and the average number of cases per outbreak was 69 compared with 33 per outbreak in England and Wales.' This difference in the average number of cases may reflect better case ascertainment in Scotland since the design and catering practices of its hospitals are likely to be similar to those in England and Wales.

The number of episodes of food poisoning in hospital staff is disturbing: $16 \%$ of the foodborne outbreaks and $15 \%$ of the cases affected, the second highest proportion after psychiatric patients. Hospital staff may introduce salmonella infection to hospital patients, and any reduction in the staffing complement due to illness might lead to a disruption of patient care. Staff canteens in hospitals are often separate from the facilities for preparing patients' food and should be included in any hygiene inspection and guidelines laid down by environmental health officers.

A circular from the Department of Health and Social Security in $1977^{10}$ advised hospital catering departments to give open access to environmental health officers, and more recently the public inquiry team $^{2}$ investigating the outbreak of food poisoning at Stanley Royd Hospital recommended that hospital kitchen premises were inspected every two years by a team of officers. The effects of this monitoring may have contributed to the reduction of outbreaks of salmonella food poisoning but may have more impact on food poisoning caused by other organisms since outbreaks of food poisoning in hospitals are now more often due to other bacteria or viruses than to salmonella (PHLS Communicable Disease Surveillance Centre, unpublished).

Two leading articles in medical journals ${ }^{112}$ recommended strengthening national surveillance of outbreaks in hospitals to improve reporting and the quality of data. Better surveillance together with improvements in infection control in hospitals, such as those described in the Cooke report, ${ }^{13}$ establishing infection control nurses and district food hygiene groups, ${ }^{14}$ and the legislation affecting crown immunity's in hospitals should lead to earlier investigation and control of outbreaks in hospitals.

I Kumarasinghe G, Hamilton WJ, Gould JD, Palmer SR, Dudgeon JA, Marshall WC An outreat of Salmonella muenchen infection in a specialist peediatric hospital. I Hosp Infect 1982;3:341-4.

2 Department of Health and Social Security. Repont of the comemince of inquiry into an oubreak of food poisoning at Stanley Rayd Hospital. London: HMSO 1986.

3 Galbraith NS, Young S. Communicable disease control: the development of a aboratory associated national epidemiological service in England and Wales. Commencity Med 1980;2:135-43.

4 Anonymous. Food poisoning and salmonellosis surveillance in England and Wales, 1980 [Editorial]. Br Med J 1981;283:924-5.

Department of Health and Social Security. Health and parsonal social services statistics for England. London: DHSS, 1982, 1985, 1986.

Welsh Office. Health and personal sacial services staristics for Wales. London: DHSS, 1979-86.

7 Abbott JD, Hepner ED, Clifford C. Salmonella infections in hospital. A report from the Public Health iaboratory Service Salmonelly Subcommittee. from the Public Health in

8 Palmer SR, Rowe B. Investigation of outbreaks of salmonella in hospitals. BrMed f 1983;287:891-3.

.


9 Collier PW, Sharp JCM, MacLood Aida F, Forbes GI, Mackay F. Food poisoning in hospitals in Scotland, 1978-87. Epidemiology and Infection 1988;101:661-7.

10 Department of Health and Social Security. Health services management: food hygiene. London: DHSS, 24 July 1977. (HC(77).)

11 Anonymous. Food poisoning in hospitals [Editorial]. Lancet 1980;i:576-7.

12 Anonymous. Stanley Royd: the epidemiological lession [Editorial]. $\mathrm{Br} \mathrm{Med} \mathcal{f}$ 1986;292:644-5.
13 Department of Health and Social Security. Hospital infection control: guidance on the control of infection in hospitals prepared by the joint DHSS/PHLS hospital infection working group. London: DHSS, 1988.

14 Chattopadhyay B. The structure and functions of a district food hygiene group. J Hosp Infect 1987;9:298-301.

15 National Health Service (Amendment) Act 1986. (CAP 66.)

(Accepted 21 February 1989)

\section{Medicine and Art}

\section{Hospital art and its problems}

\section{Tony Delamothe}

Works of art have been commissioned by hospitals for almost as long as hospitals have existed, and as the function of hospitals has changed so has the purpose of their commissioned art. In earlier centuries paintings on hospital walls prepared patients for the next world, gave consolation, or extolled the virtues of Christian charity. As hospitals have become places where patients go to get better the claims made for art have changed too. Art now heals. According to Peter Senior, director of Arts for Health ${ }^{1}$ and someone who has done much to promote art's healing powers, "Art can benefit everyone and can play a part in maintaining and improving health of the mind and body."

Whether this is true or not is now beside the point Sufficient people believe it, and others are prepared to go along with it if dreary hospital interiors improve. In the past decade hundreds of hospital based arts projects have set about beautifying the NHS's motley inheritance of property, which ranges in style from Victorian poorhouse to the vapid chirpiness of the 1970s. The triumphant culmination of this movement was a whole hospital-St Mary's, Newport, Isle of Wight-designed from scratch with future artistic embellishment in mind. ${ }^{2}$ Prophets such as Peter Senior deserve some of the credit for this but so too does the Department of Health for its enlightened encouragement of architects and planners in planning for art in buildings.

British Medical Journal, London WC1H 9JR Tony Delamothe, $\mathrm{MD}$ assistant editor

BrMed f 1989;298:1164-5

\section{Taking stock}

A recent seminar held in conjunction with the fourth international contemporary art fair in London heard of the job opportunities created for artists, craftsmen, and arts administrators by this sudden change of direction.
It was also suggested that after this first flush of enthusiasm now may be a good time to take stock. Even taking on a modern day Michelangelo to brighten up the ceiling of an outpatient department or a da Vinci to do something about a day room may lead to more problems than artist, patients, or staff think it is worth.

Sarah Hosking, arts coordinator of the Basingstoke and North Hampshire Health Authority, identified at least three possible sources of conflict: differences between the artist and the client (usually the NHS), differences between community art and mainstream art, and problems relating to the client.

Anyone doubting C P Snow's formulation of "two cultures;" it was politely implied by several speakers at the seminar, should mix for a time with doctors and hospital administrators. They may know what they do not like, but they certainly do not know much about art. Hackles are raised immediately by the assumption that the money has come out of some overstretched budget ("How come they've got money for this when the $x$ ray department is teetering on the brink?"). Invariably the money has not come out of such a budget: most hospitals have provided little more than free lunches for the artists during their work. Money, arts administrators are finding, is often the least of their problems, with many local and national statutory and voluntary bodies keen to support such initiatives. (Arts for Health has a list.)

On the differences between community art - usually cheap and cheerful, four students and a foreman - and more mainstream art it is Ms Hosking's opinion that given the milage of NHS corridors there was ample room for both. Some community art projects in hospital and elsewhere have come up with extremely dubious results. Others, such as Manchester Psychiatric Day Hospital's Head for the Hills, a mural to which

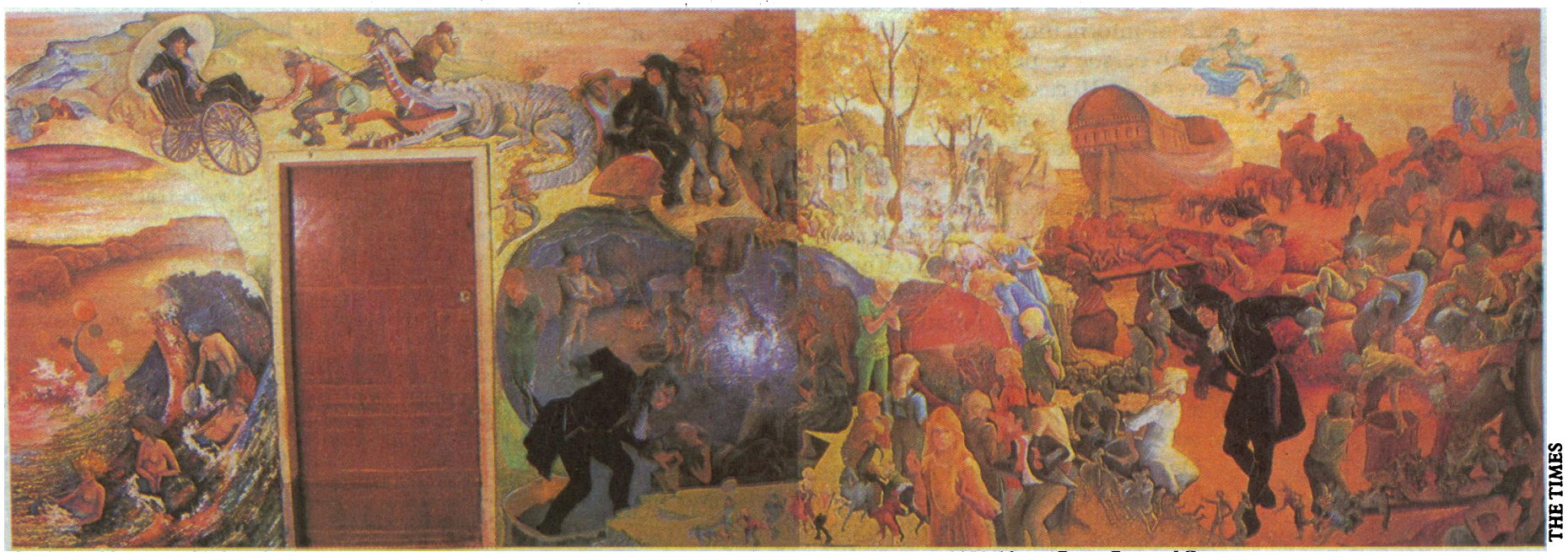

Section-About one thind - of Edwand Caswell's 21-9 m mural based on "Peter Pan" at The Hospital for Sick Children, Great Ormond Street 